\title{
Haematological and Immunological Responses in Juvenile Sea Bass (Dicentrarchus labrax L.) After Short-Term Acute Stress
}

\author{
Giulia Maricchiolo*, Gabriella Caruso and Lucrezia Genovese
}

National Research Council, Istituto per l'Ambiente Marino Costiero, Messina, Italy

\begin{abstract}
The physiological effects of acute stress (induced by an intraperitoneal injection) on the haematocrit, haemoglobin, serum cortisol and glucose, haemagglutinins and lysozyme were investigated in juvenile sea bass Dicentrarchus labrax. A total of 40 fish were subjected to an intraperitoneal injection. Eight fish were sampled at 0, 2, 4, 24 and $48 \mathrm{~h}$ after acute stress and compared to unstressed fish (controls) sacrificed at the same times. Intraperitoneal injection resulted in significant changes in cortisol and glucose 4 and 2 hours after exposure to stress, respectively, but not in haematocrit and haemoglobin levels. No significant differences between stressed and control fish were recorded for lysozyme content and haemagglutinating activity throughout the experiment. In juvenile sea bass acute stress caused by intraperitoneal injection was mostly associated with the increase in common stress indicators (cortisol and glucose), while no clear response in terms of non-specific immune parameters was evidenced.
\end{abstract}

Key Words: Dicentrarchus labrax, acute stress, intraperitoneal injection, cortisol, glucose, haematocrit, haemoglobin, nonspecific immune parameters.

\section{INTRODUCTION}

Many husbandry activities in intensive aquaculture, like handling, transport and vaccination, lead to stress in reared organisms which, if intense or chronic, can eventually lead to fish welfare impairment.

It is well known that high welfare of farmed fish means a good production [1], as proved in many other terrestrial animals. Then research on the effects of aquaculture procedures on welfare is extremely important to produce data and recommendations for best practice and future legislation.

As in other vertebrates, fish experiencing stress show a number of physiological changes; therefore it is important to understand the physiological response to stress response in fish.

In Teleosts stressors elicit a typical "stress response" of adaptive value [2] that is characterized by an immediate release of stress hormones followed by a series of biochemical and physiological changes [3].

In particular fish react to stress with a primary neuroendocrine response, represented by a rapid hypersecretion of catecholamines (adrenaline and noradrenaline) and corticosteroids (mainly cortisol) into the blood stream [4].

As a result of their high levels in the circulatory system, a wide range of secondary responses can be observed; in particular secondary responses are defined as the subsequent actions and effects of these hormones at blood and tissue level, and include disturbance of the metabolic and hydromineral balance.

*Address correspondence to this author at the National Research Council, Istituto per l'Ambiente Marino Costiero, Spianata S. Raineri, 86 - 98122 Messina, Italy; Tel: (+39) 90 669003; Fax: (+39) 90669007 ;

E-mail: giulia.maricchiolo@iamc.cnr.it
Tertiary responses include behavioural modifications, implications for fish growth and reproduction and increased sussceptibility to diseases $[5,6]$.

A variety of biochemical measurements is used as indicators of stress in fish.

Among the most frequently measured variables, there are levels of circulating corticosteroid hormones (mainly cortisol) and glucose, lactate, haemoglobin, proteins and haematocrit [1]. In addition, some components of innate immune system (e.g. lysozyme, haemolytic and haemagglutinating activity) are used as indicators of immunocompetence in fish exposed to stress [7-10].

There is extensive literature on the physiological responses of fish to a wide variety of acute and chronic stressors [2, 11-15].

Chronic stressors are usually associated with reduced growth, changes in reproductive function and behaviour (changes in colour, breathing frequency, social and swimming behaviour) [5] and increased susceptibility to disease [16].

On the contrary acute stressors can have different effect in fish; if stress is severe enough, it can have lethal consequences $[17,18]$ but can also lead to an enhancement of fish immune response (increased concentrations of specific plasma protein, such as lysozyme or complement) and to a better protection against any possible damage [19, 20].

The magnitude and duration of biochemical stress response can vary between species [6, 21, 22].

Most research on the acute stress has been focused on handling $[6,19,23,24]$ and capture [25-28] but no information is available on physiological effects of vaccination. 
Indeed vaccination, especially when practised via intraperitoneal (considered the most effective method for delivering vaccines to fish) could cause side-effects and animal welfare impairing.

The purpose of the present study was to simulate intraperitoneal vaccination in order to investigate possible physiological side-effects of this practice (a typical short-term acute stress) in juvenile sea bass Dicentrarchus labrax (Linneo, 1758) evaluating changes occurring in some physiological parameters.

In particular the panel of assayed parameters included measures of haemoglobin and haematocrit values, serum glucose and cortisol levels, haemagglutinating activity and the content of lysozyme in plasma, kidney and mucus.

\section{MATERIALS AND METHODOLOGY}

\section{Experimental Design and Samples Collection}

Juveniles of sea bass (D. labrax) were obtained from a commercial Sicilian fish farm.

The study was carried out at the facilities of the Institute for Coastal Marine Environment of Messina.

A group of 80 fish (mean body weight $10.0 \mathrm{~g}$ ) were randomly distributed in 10 tanks of 100-L volume (eight fish for tank, to avoid the stress repeated capture) and maintained for 2 weeks to allow acclimation.

During this adaptation period fish were fed with a commercial pellets for carnivorous fish administered until satiation.

Each tank was supplied with a constant aerated flow of seawater. The water temperature was $24-25{ }^{\circ} \mathrm{C}$, $\mathrm{pH}$ was 8.2 and dissolved oxygen was 7-8 $\mathrm{mg} \mathrm{L}^{-1}$. Photoperiod was kept natural.

Before stressor application fish were starved for $18 \mathrm{~h}$. Fasting before fish handling is a common practice in aquaculture especially when using anaesthesia; indeed it avoids the risk of regurgitation which can obstruct the gills and dirty water; normally fasting for at least 24 hours is recommended, in this study we limited fasting to 18 hours. After this period, fish from 5 tanks were anesthetized in MS-222 (tricaine methamesulfonate, $0.1 \mathrm{gL}^{-1}$, Sigma-Aldrich), subjected to an intraperitoneal injection (IP) (without injecting any substance) and then put again in their home tanks. A control group was left undisturbed under the same rearing conditions as the stressed group.

At predetermined time intervals $(0,2,4,24$ and $48 \mathrm{~h}$ post stress) eight stressed fish from each tank were quickly netted, killed by spiking method (destruction of the brain by a sharp spike) and sampled.

Fish were sampled at the same time of each day (at 10.00 am) since the parameters measured (especially cortisol and glucose) are subject to diurnal variations.

Sampling periods were selected on the basis of literature concerning the acute stress response [29], where physiological effects of acute stress are short-term effects that usually occur especially in the first hours after disturbance (up to 24$48 \mathrm{~h})$.
Simultaneously, eight unstressed fish were sacrificed at the same time intervals to be used as controls.

To avoid a sampling-induced stress response the time between dipnet introduction and withdrawal lasted less than 34 minutes for group (withdrawal was carried out simultaneously by two operators).

Blood samples were drawn separately from the caudal vein of each individual, in order to monitor haematological and non-specific immune defence parameters. Small volumes of blood, collected in heparinised (14 International Units $\mathrm{mL}^{-1}$ ) tubes, were used for the immediate determination of haematocrit and haemoglobin values. The remaining fraction was centrifuged and the obtained plasma was stored at $-80^{\circ} \mathrm{C}$ for further lysozyme assay.

In order to extract the serum for the determination of cortisol, glucose and haemagglutinins, blood samples not treated with heparin, were allowed to clot at $4^{\circ} \mathrm{C}$, centrifuged at $1500 \mathrm{~g}$ for 10 minute and stored at $-80^{\circ} \mathrm{C}$ until analysis.

From each fish mucus and kidney samples were also collected for lysozyme measures.

\section{Haematological, Biochemical and Non-Specific Immune Response Parameters}

Serum cortisol concentration was determined by use of a commercially available enzyme-linked (ELISA) immunoassay kit (Alpha Diagnostic International, USA).

Serum glucose level was determined by a commercial kit based on the reaction of GOD-POD (Glucose Oxidase-Peroxidase) (Sclavo Diagnostics, Italy).

Haematocrit value (\% red blood cell) was determined in heparinised capillary tubes after centrifugation in a standard microhaematocrit centrifuge at $12.000 \mathrm{~g}$ for 10 minute and comparison of the capillary tube with a reference scale.

Blood haemoglobin concentration was measured colorimetrically by use a cyanmethemoglobin method-based kit (Sclavo Diagnostics, Italy).

Aliquots of plasma, mucus and kidney were assayed for lysozyme content. The assay was performed using the radial diffusion method in agarose plates containing $1 \%$ agar added with $0.05 \%$ lyophilised Micrococcus lysodeikticus (SigmaAldrich, Italy) as the substrate, dissolved in $\mathrm{pH} 5.75$ phosphate buffer. Lysozyme content was evaluated by measuring the diameter of lysis produced after incubation at $30^{\circ} \mathrm{C}$ for $22 \mathrm{~h}$, which was converted into Units of lysozyme per $\mathrm{mL}$ of sample $\left(\mathrm{U} \mathrm{mL}^{-1}\right)$ through calibration with known amounts of egg-white lysozyme (Sigma-Aldrich) used as the standard $[30,31]$.

The haemagglutinating activity of the serum was determined in 96-well microtiter U plates (NUNC INC., Denmark) according to the twofold serial dilution procedure. After addition with a $2 \%(\mathrm{v} / \mathrm{v})$ sheep erythrocyte suspension in PBS, serial dilutions of the serum were incubated at $35^{\circ} \mathrm{C}$ for $1 \mathrm{~h}$ and at $+4^{\circ} \mathrm{C}$ overnight; results were reported as $\log 2$ value of the final serum dilution showing visible agglutination. 


\section{Statistical Analysis}

All results are expressed as means \pm SE. Data were subjected to two-way analysis of variance (ANOVA) to assess the effects of single variables (groups, sampling times) and of their interaction on physiological parameters. In the design of the statistical analysis groups (control and IP) and sampling times (hours) represented the two main factors. When a significant interaction was found, single comparison between data were performed using one-factor ANOVA. Differences were considered statistically significant when $\mathrm{p}$ $\leq 0.05$.

\section{RESULTS}

No mortality was observed throughout the experiment.

The effects of stress on haematological and immunological parameters are shown in Figs. (1-8).

Fish subjected to stress did not differ significantly from controls in either haematocrit or haemoglobin concentration (Figs. 1-2).

Cortisol levels (ng $\mathrm{mL}^{-1}$ ) ranged from 184.13 to 381.82 in control fish and from 181.76 to 620.45 in stressed fish.

Significant elevation in cortisol levels was observed in fish that experienced acute stress.

Serum cortisol markedly increases 2 hours after disturbance, and the peak was detected after 4 hours when cortisol reaches a maximum concentration of $620.45 \mathrm{ng} \mathrm{mL}^{-1}$. This value was significantly $(\mathrm{p}<0.01)$ higher than control group.

Subsequently, serum cortisol value decreased but, after $48 \mathrm{~h}$, it remained significantly higher than in the control group $(\mathrm{p}<0.05)$ (Fig. 3).

Serum glucose $\left(\mathrm{mg} \mathrm{dL}^{-1}\right)$ ranged from 52.39 to 101.06 and from 52.40 to 121.40 in control and stressed fish, respectively.

Unlike cortisol, serum glucose, in stressed fish, raised significantly after 2 hours, reaching a maximum value of $121.40 \mathrm{mg} \mathrm{dL}^{-1}$. This value was significantly higher than control group $(\mathrm{p}<0.01)$.

After two hours glycaemia rapidly decreased and concentration remained significantly $(p<0.01)$ lower than control group, up to the end of the trial (48 h post stress) (Fig. 4).

Lysozyme content varied differently depending on the tissue or organ where it was measured (Figs. 5-7).

On average, the lowest values were recorded in the plasma of the control group, whose lysozyme values ranged from 1.11 to $1.24 \mathrm{U} \mathrm{mL}^{-1}$, compared to the stressed group whose values increased, ranging from 0.99 to $1.48 \mathrm{U} \mathrm{mL}^{-1}$.

Although not statistically significant by ANOVA, the highest difference in the lysozyme values between the two groups was found 4 hours after intraperitoneal vaccination (Fig. 5).

In the mucus of the control group lysozyme content ranged from 1.48 to $1.79 \mathrm{U} \mathrm{mL}^{-1}$, while in the stressed one lower lysozyme values were measured, ranging from 1.48 to 1.73 $\mathrm{U} \mathrm{mL}^{-1}$. No significant differences between the two groups were recorded throughout the experiment (Fig. 6).
In the kidney lysozyme values ranged from 1.24 to 2.22 $\mathrm{U} \mathrm{mL}^{-1}$ in the control group, whereas in the stressed one values were lower, ranging from 1.11 to $1.73 \mathrm{U} \mathrm{mL}^{-1}$; a slight increase in lysozyme levels was recorded 4 hours after stress (Fig. 7).

The haemagglutinating activity was generally lower in the stressed fish, where $\log 2$ values ranged from 3 to 4 , compared to the values recorded in the control fish, ranging from 4 to 5 . The activity slightly increased 4 hours after stress, although a similar trend was observed in control group; afterward; stressed fish maintained values similar to those measured in control ones (Fig. 8).

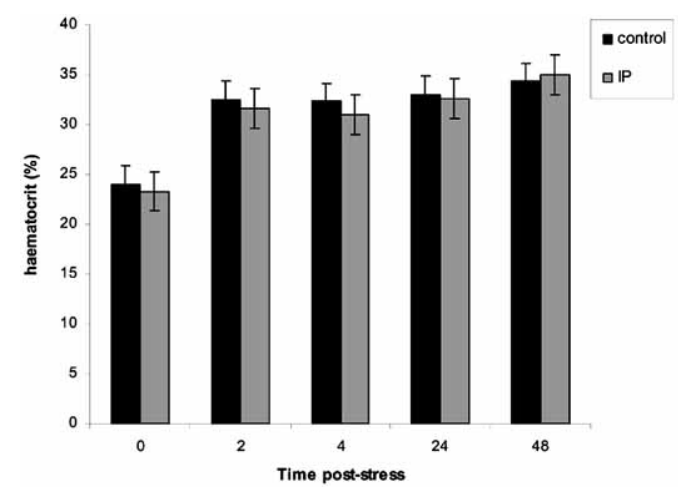

Fig. (1). Haematocrit value in control and stressed (IP) juvenile sea bass. Values are means $\pm \operatorname{SEM}(n=8)$.

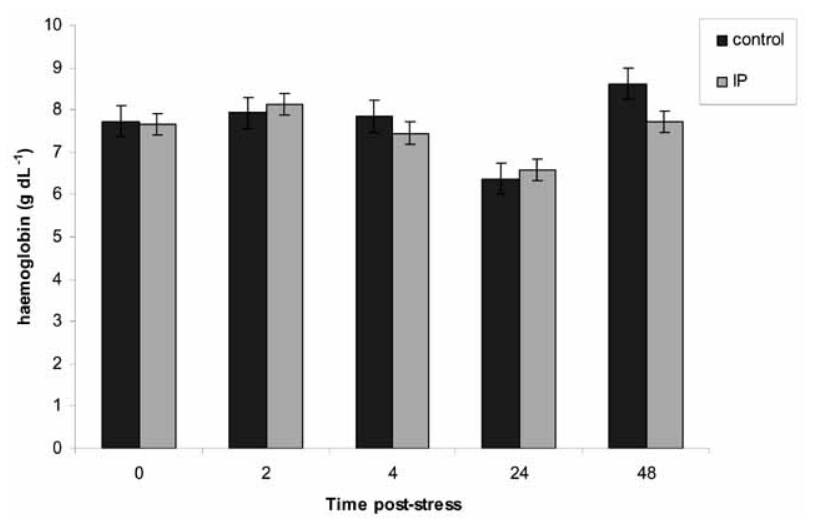

Fig. (2). Haemoglobin concentration in control and stressed (IP) juvenile sea bream. Values are means $\pm \operatorname{SEM}(n=8)$.

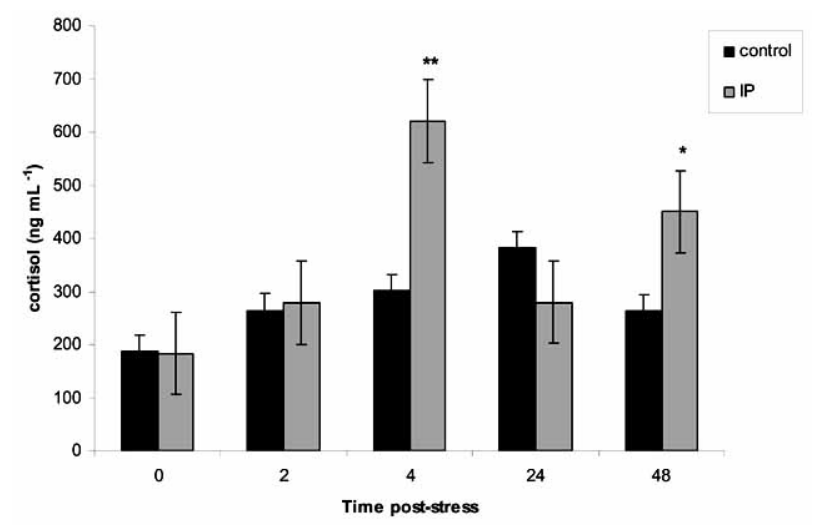

Fig. (3). Cortisol concentration in control and stressed (IP) juvenile sea bass. Values are means $\pm \operatorname{SEM}(n=8)$. * Significantly different from the control $*(\mathrm{P} \leq 0.05) * *(\mathrm{P} \leq 0.01)$. 


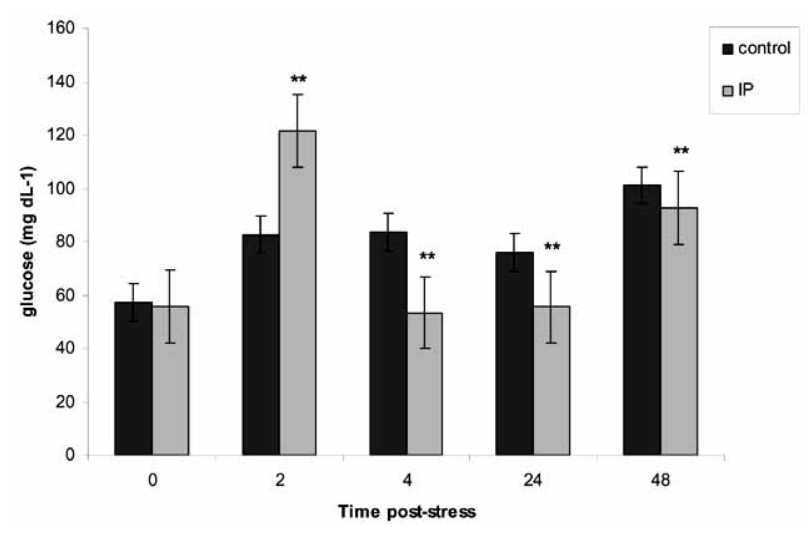

Fig. (4). Glucose concentration in control and stressed (IP) juvenile sea bass. Values are means $\pm \operatorname{SEM}(n=8)$. $*$ Significantly different from the control $* *(\mathrm{P} \leq 0.01)$.

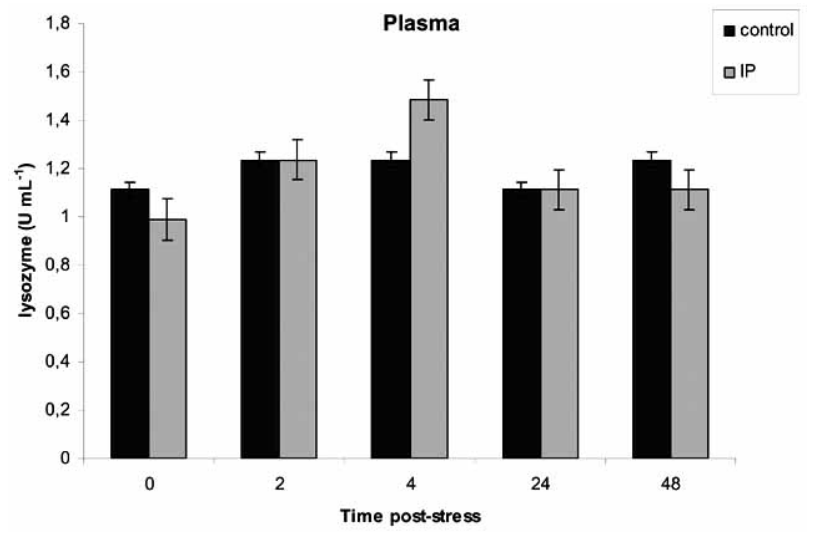

Fig. (5). Lysozyme content (in Units $\mathrm{mL}^{-1}$ ) in the plasma of control and stressed (IP) juvenile sea bass. Values are means \pm SEM $(n=$ $8)$.

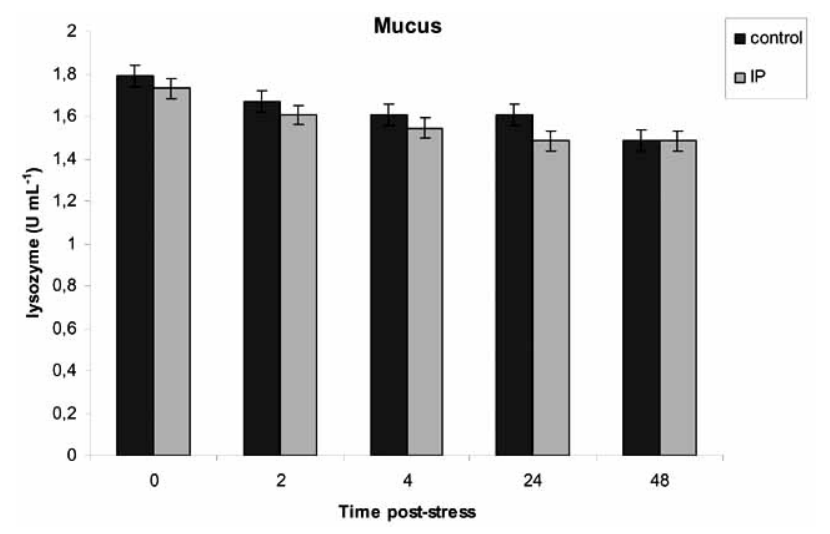

Fig. (6). Lysozyme content (in Units $\mathrm{ml}^{-1}$ ) in the mucus of control and stressed (IP) juvenile sea bass. Values are means \pm SEM $(n=$ 8).

\section{DISCUSSION}

In aquaculture practices the understanding of fish stress response is essential to avoid stress-related problems, and to improve fish quality, optimizing productions.

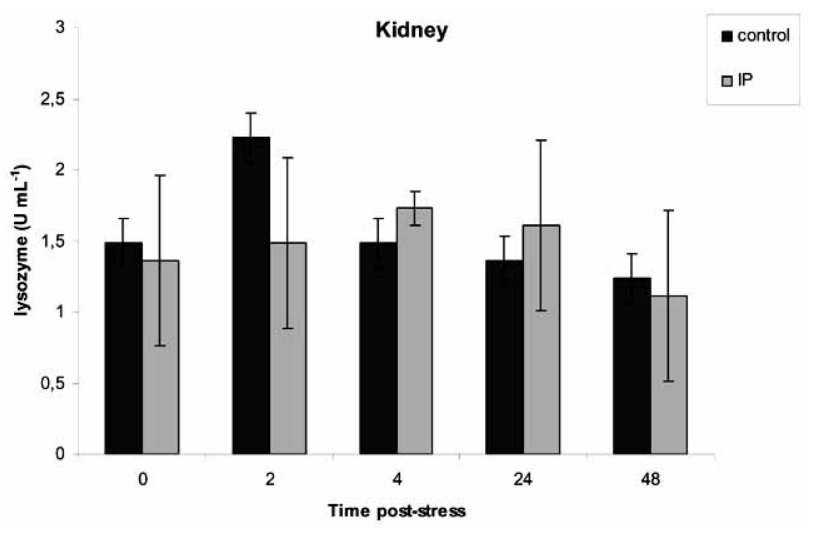

Fig. (7). Lysozyme content (in Units $\mathrm{mL}^{-1}$ ) in the kidney of control and stressed (IP) juvenile sea bass. Values are means \pm SEM $(n=$ $8)$.

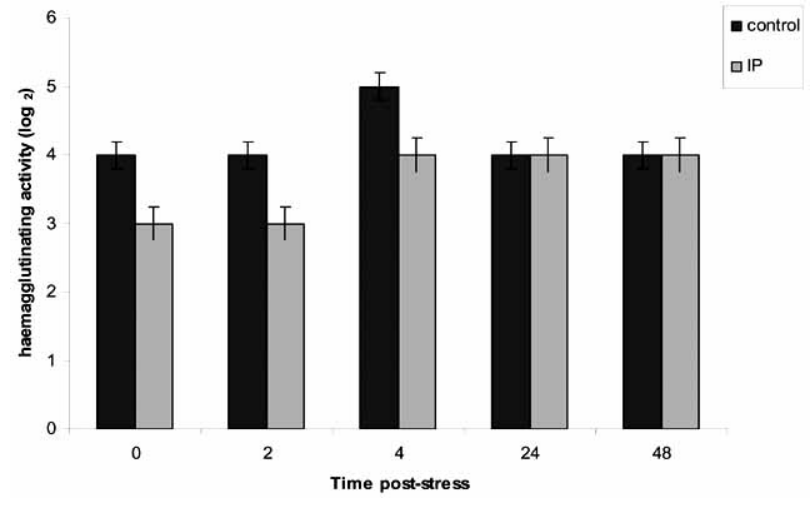

Fig. (8). Haemagglutinating activity (reported as $\log 2$ values of the final serum dilution showing visible agglutination) in control and stressed (IP) juvenile sea bass. Values are means $\pm \operatorname{SEM}(n=8)$.

Among the aquaculture practices that may cause stress intraperitoneal vaccination should be taken into consideration because of its potential adverse effects.

Much attention has been focused on the effects of vaccination upon growth, feed intake and feed conversion efficiency [32-39] and on tissue lesions and intra-abdominal adhesions [32, 34, 35, 40, 41]. To date, no study has been performed on physiological stress response.

To our knowledge, this experiment is the first performed in sea bass dealing with the study of physiological responses following intraperitoneal vaccination simulating an acute stress condition.

As in other vertebrates, fish experiencing stress show a number of physiological changes that are expressed through a number of particular indicators [2].

In the present study, serum cortisol was measured as primary stress response, serum glucose, haematocrit and haemoglobin as secondary stress response, and lysozyme and haemagglutinating activities served as measures of innate immune response.

The specific literature shows that the stress responses in fish varies both with the nature of the stress (acute or chronic) and with the species. Also, in the case of an acute stress, the 
time course of stress response depends on the severity and duration of the stress itself [42].

Haematocrit and haemoglobin levels are frequently used as secondary stress haematic indicators [2, 43, 44]. However available data are often conflicting, depending on the type of stress imposed.

Tort et al. (1994) [45] and Altimiras et al. (1994) [46] reported a decrease of haematocrit value, in response to hypoosmotic shock, in sea bream, Sparus aurata. On the other hand, Benfey \& Biron (2000) [47] showed that acute stress causes an elevation in haematocrit value, in contrast with above results. Moreover, Mazur \& Iwama (1993) [48] reported no changes in haematocrit contents in chinook salmon subjected to handling stress.

Usually haemoglobin concentration seems to be less influenced by acute stress and no changes in this parameter were found as a consequence of acute handling in different fish species [47, 49, 50]. In the present study, no significant variations in these parameters was observed in juvenile sea bass subjected IP vaccination compared to control fish.

The present data support the studies where it is clear that these haematological indicators of secondary stress response are mainly displayed in chronic stress situations [24]. It has been shown that high stocking density, considered as an aquaculture-related chronic stressor [43] produce on juveniles of gilthead seabream, haemoconcentration, as a strategy for increasing oxygen carrying capacity of blood during periods of high energy demand [51-53].

Blood cortisol levels are widely used as an indicator of stress condition [2] because of the extreme sensitivity of the hypothalamo-pituitary-interrenal (HPI) axis.

In fish acute stress elicits increases in corticosteroid levels [18, 54, 55].

In general the cortisol response is transient and the time required for the circulating levels of this hormone return to normal depends on the intensity of the stressors [41].

In this study, IP injection provoked a characteristic acute stress response in sea bass, with cortisol peak reaching $620.45 \mathrm{ng} \mathrm{mL}^{-1}, 4 \mathrm{~h}$ after the stress.

Our results, also, show that a period of $48 \mathrm{~h}$ was not sufficient enough to fish to recover to pre-stress cortisol levels.

In other teleosts, such as Sparus aurata [8, 55, 56], Salmo trutta [6] and Oreochromis niloticus [57] the same time period is sufficient to observe a return to normality.

In addition, the present study gave the opportunity to observe the daily variation of cortisol levels in captive juveniles sea bass over a $24 \mathrm{~h}$ period (control group).

Daily variations of plasma cortisol in sea bass have been reported to be mainly associated with feeding times or with seasons $[58,59]$.

Planas et al. 1990 [59] compared daily changes of cortisol during four different months of the year and reported significant daily variations of this parameter in September when the water temperature reached the highest value (25.7 $27.2^{\circ} \mathrm{C}$ ). Our study was performed in June when water temperature was $24-25^{\circ} \mathrm{C}$; in juvenile sea bass cortisol fluctuated daily from 100 to $200 \mathrm{ng} \mathrm{mL}^{-1}$ and these values as well as water temperature were similar to those reported by the Authors cited above.

Blood glucose levels have been also described to be affected by acute and chronic stress [2, 43, 60].

The response of sea bass to IP injection consisted of a hyperglycaemia $2 \mathrm{~h}$ after stress, while hypoglycaemia began after $4 \mathrm{~h}$, and lasted for $48 \mathrm{~h}$ post-stress.

The rapid rise in glucose levels found in juvenile sea bass has been demonstrated in other teleosts exposed to acute stressors [6, 24, 31, 61].

The hyperglycaemia observed in these studies has been shown to be mediated by catecholamines [3, 62], which stimulate glucose release from liver, through glycogenolysis and gluconeogenesis [62-64].

Several factors (rearing history, nutritional status, environmental temperature and species) can affect fish stress response and glucose clearance rate [65].

The hypoglycemia observed in sea bass at $4 \mathrm{~h}$ post-stress is difficult to explain.

This might be ascribed to a particularly sensitive compensation process of blood glycemia which causes a rapid fall of glucose levels. Hypoglycemia, in turn, triggers the production of inhibitor hormones, such as glucagone, adrenaline and corticosteroids, which stimulate liver (and other organs) to release reserves to increase, again, glycaemia. This could explain the increase in cortisol observed $48 \mathrm{~h}$ after stress which corresponds to a rise in blood glucose.

Concerning the effects of IP vaccination on non-specific immune response parameters, it is generally accepted that in fish stress causes decreased immune function and increased susceptibility to disease, although the relationships between stressors, immune reactivity and disease incidence are still poorly understood [66].

In D. labrax, intraperitoneal vaccination caused increased lysozyme levels in plasma, whereas an opposite trend was observed in mucus and kidney. No significant differences between stressed and control fish were detected 4 hours after intraperitoneal vaccination.

In literature, the physiological response of fish to acute stress conditions in terms of non-specific immune response is still poorly investigated and only a few studies have focused on the effects induced on lysozyme activity by stressors such as handling or transport, frequent in fish culture $[10,66]$.

Lysozyme is an important enzyme involved in the nonspecific immune response of many fish species [10]; it acts as an important factor in protecting fish against bacterial pathogens, due to its antibacterial properties against both Gram positive and negative bacteria.

Lysozyme content decreased in rainbow trout exposed to severe stress (such as that caused by transport), while it increased following less stressful conditions, indicating that the behaviour of this parameter may be different according to the strength of the stressor and the condition of each individual [66]. 
In rainbow trout, acute stressors such as handling, confinement and transport lasting 10 minutes were associated with significant increases in lysozyme activity in the serum, in agreement with what found in our study [67].

In rainbow trout subject to acute stress induced by bleeding an increase of lysozyme was noticed within $1 \mathrm{~h}$ [19], suggesting that acute stress may determine short-term enhancement of this defence molecule, in contrast to chronic stress, which is usually immunosuppressive.

Assuming that changes in lysozyme activity reflect the modulation of the defence system, the peak displayed by lysozyme, in kidney and plasma, 4 hours after intraperitoneal injection could suggest its initial activation, which is followed by its decrease to initial levels, similarly to what previously found in rainbow trout $[66,19]$.

The increase in lysozyme levels is related to the cells that are responsible for its secretion; increased numbers of leucocytes were also observed in the head kidney of juvenile coho salmon (Oncorhynchus kisutch) [68] within $24 \mathrm{~h}$ of the stress.

In contrast, in Atlantic salmon IP vaccination [69] was found to elicit a stress response, consisting in the reduction of antibody producing cells and lymphopenia, whose duration exceeded that elicited by other acute stressors such as holding in a dip-net for $30 \mathrm{~s}$ [70] or crowding [6].

With respect to the haemagglutinating activity, agglutinins are recognised to be a key component of innate immune system in many fish species, which are active against homologous or heterologous red blood cells $[8,10]$.

The trend shown in this study by the haemagglutinating activity values suggests that this parameter fluctuated with no apparent relationship with the induction of acute stress.

The increase recorded 4 hours after intraperitoneal injection is in contrast with previous research showing the progressive decrease in haemagglutination activity in gilthead seabream juveniles exposed to repeated acute stress consisting in chasing with a net for 5 minutes over 14 days [7, 71]. In the same species, chronic stress induced by crowding caused immunodepression, as suggested by decreases in haemagglutination titre observed after 9 days [72].

\section{CONCLUSIONS}

This study contributes to current knowledge on fish response to stress experienced as a consequence of aquaculture practices by adding some data on physiological effects similar to those produced by vaccination practice.

According to the time course of the parameters assayed in the present investigation it can be concluded that in Dicentrarchus labrax the acute response is commonly associated with the increase in cortisol and glucose levels, while it is not reflected by a clear response in terms of non-specific immune parameters, as suggested by the lack of statistical differences in lysozyme and haemagglutinating activities between stressed and control fish.

Results obtained show that juveniles of sea bass subjected to an intraperitoneal injection experience acute stress as demonstrated by neuroendocrine system activation.
The length of experiment did not allow us to observe sea bass recovery to normality suggesting that the physiological response of sea bass is significant enough to determine variations in overall welfare status. However further study is needed to determine how long the stress response lasts.

Our results confirm that the time needed for complete recovery is species-specific and is a function of duration and severity of the applied stress. Hence the need to know how each species react to routine practices in aquaculture.

\section{REFERENCES}

[1] Poli BM, Parisi G, Scappini F, Zampacavallo G. Fish welfare and quality as affected by pre-slaughter and slaughter management. Aquaculture Int 2005; 13: 29-49.

[2] Wendelaar Bonga SE. The stress response in fish. Physiol Rev 1997; 77: 591-625.

[3] Mazeaud MM, Mazeaud F, Donaldson EM. Primary and secondary effects of stress in fish: some new data with a general review. Trans Am Fish Soc 1977; 106: 201-212

[4] Pickering AD, Ed. Stress in fish. Academic Press London 1981.

[5] Parkhurst NW, Van der Kraak G. In: Iwama GK, Pickering AD, Sumpter JP, Schreck CB, Eds. Fish stress and Health in Aquaculture. UK. Cambridge University Press 1997; 73-93.

[6] Pickering AD, Pottinger TG, Christie P. Recovery of the brown trout, Salmo trutta L., from acute handling stress: a time course of study. J Fish Biol 1982; 20: 229-244.

[7] Sunyer JO, Gomez E, Navarro V, Quesada H, Tort L. Physiological responses and depression of humoral components of the immune system in gilthead seabream (Sparus aurata) following daily acute stress. Can J Fish Aquat Sci 1995; 52: 2339-2346.

[8] Tort L, Gòmez E, Montero D, Sunyer JO. Serum haemolytic and agglutinating activity as indicators of fish immunocompetence: their suitability in stress and dietary studies. Aquaculture Int 1996; 4: $31-41$.

[9] Caruso G, Genovese L, Maricchiolo G, Modica A. Haematological, biochemical and immunological parameters as stress indicators in Dicentrarchus labrax and Sparus aurata farmed in off-shore cages. Aquaculture Int 2005; 13: 67-73.

[10] Tort L, Balasch JC, MacKenzie S. Fish health challenge after stress. Indicators of immunocompetence. Contrib Sci 2004; 2: 443454.

[11] Iwama G, Pickering A, Sumpter J, Scherck C, Eds. Fish Stress and Health in Aquaculture. Cambridge University Press 1997.

[12] Barton BA. Salmonid fishes differ in their cortisol and glucose responses to handling and transport stress. N Am J Aquaculture 2000; 62: 12-18.

[13] Barton BA. Stress in fishes: a diversity of responses with particular reference to changes in circulating corticosteroids. Integr Comp Biol 2002; 42: 517-525.

[14] FSBI [Fisheries Society of the British Isles] [Homepage on the Internet]. Fish Welfare. Breifing Report 2. Granta Information system 2002. Available from: http://www.le.ac.uk/biology/fsbi/welfare.pdf

[15] Conte FS. Stress and welfare of cultured fish. Appl Anim Behav Sci 2004; 86: 205-223.

[16] Wedemeyer GA, McLeay DJ. In: Pickering AD, Ed. Stress in fish. London. Academic Press 1981; 247-275.

[17] Wedemeyer GA. Some physiological consequences of handling stress in the juvenile coho salmon (Onchorhyncus kisutch) and rainbow trout (Salmo gairdneri) to handling and crowding in intensive fish culture. J Fish Res Board 1972; 33: 2699-2702.

[18] Strange R, Schreck CB, Ewing RD. Cortisol concentration in confined juvenile chinook salmon (Onchorhyncus tshawytscha). Trans Am Fish Soc 1978; 107: 812-819.

[19] Demers NE, Bayne CJ. The immediate effects of stress on hormones and plasma lysozyme in rainbow trout. Dev Comp Immunol 1997; 4: 363-373.

[20] Ruis MAW, Bayne CJ. Effects of acute stress on blood clotting and yeast killing by phagocytes of rainbow trout. J Aquat Anim Health 1997; 9: 190-195.

[21] Wedemeyer GA. Physiological response of juvenile coho salmon (Onchorhyncus kisutch) and rainbow trout (Salmo gairdneri) to 
handling and crowding stress in intensive fish culture. J Fish Res Board Can 1976; 33: 2699-2702.

[22] Davis KB, Parker NC. Plasma corticosteroid and chloride dynamics in rainbow trout, Atlantic salmon, and lake trout during and after stress. Aquaculture 1983; 32: 189-194.

[23] Tort L, Montero D, Robaina L, Fernandèz-Palacios H, Izquierdo MS. Consistency of stress responses to repeated handling in the gilthead sea bream Sparus aurata Linnaeus, 1758. Aquaculture Res 2001; 32: 593-598.

[24] Morales AE, Cardenete G, Abellàn E, Garcìa-Rejon L. Stressrelated physiological responses to handling in commom dentex (Dentex dentex Linnaeus, 1758). Aquaculture Res 2005; 36: 33-40.

[25] Barcellos LJG, Woehl VM, Wassermann GF, Quevedo RM, Ittzés I, Krieger MH. Plasma levels of cortisol and glucose in responses to capture and tank transference in Rhamdia quelen (Quoy \& Gaimard), a South American catfish. Aquaculture Res 2001; 32: 121123

[26] da Rocha MR, Carvalho EG, Urbinati EM. Physiological responses associated with capture and crowding stress in matrinxã Brycon cephalus (Gunther, 1869). Aquaculture Res 2004; 35: 245-249.

[27] Parkunst NW, Sharples DF. Effect of capture and confinement on plasma cortisol concentrations in the snapper Pagrus auratus. Aust J Mar Freshwater Res 1992; 42: 345-356.

[28] Grutter AS, Parkunst NW. The effects of capture, handling, confinement and ectoparasite on plasma levels of cortisol, glucose and lactate in the coral reef fish Hemigymnus melapterus. J Fish Biol 2000; 57: 391-401.

[29] Arends RJ, Mancera JM, Mũnoz JL, Wendelaar Bonga SE, Flik G. The stress response of the gilthead sea bream (Sparus aurata L.) to air exposure and confinement. J Endocrinol 1999; 163: 149-157.

[30] Osserman EF, Lawlor DP. Serum and urinary lysozyme (Muramidase) in monocyte and monomyelocytic leukaemia. J Exp Med 1966; 124: 921-951.

[31] Hjelmeland K, Christie M, Raa J. Skin mucus protease from rainbow trout, Salmo gairdneri Richardson, and its biological significance. J Fish Biol 1983; 23: 13-22.

[32] Midtlyng PJ, Reitan LJ, Speilberg L. Experimental studies in the efficacy and side-effects of intraperitoneal vaccination of Atlantic salmon (Salmo salar L) against furuncolosis. Fish Shell Immunol 1995; 6: 335-350.

[33] Beamish FW, Sitja-Bobadilla A, Jebbink JA, Woo PT. Bioenergetic cost of cryptobiosis in fish: rainbow trout Onchorhyncus mykiss infected with Cryptobia salmostica and with an attenuated live vaccine. Dis Aquat Org 1996; 25: 1-8.

[34] Midtlyng PJ. A field study on intraperitoneal vaccination of Atlantic salmon (Salmo salar L) against furuncolosis. Fish Shell Immunol 1996; 6: 553-565.

[35] Hoel K, Lilehaug A. Adjuvant activity of polar glycopeptidolipids from Mucobacterium chelonae in experimental vaccines against Aeromonas salmonicida in salmonid fish. Fish Shell Immunol 1997; 7: 365-376

[36] Kitlen JW, Heibol EK, Zinc T, Byatt JC, Warming K, McLean E. Growth and respirstoty burst activity in rainbow trout treated with growth hormone and bivalent vaccine. Fish Shell Immunol 1997; 7: 297-304.

[37] Espersen TW, Fønss A, Vestbö BD, McLean E, Teskeredžić Z, Teskeredžić E. An industrial-scale study on the impact of vaccination upon rainbow trout performances. Ribarstvo1999; 4: 149-161.

[38] Rønsholdt B, McLean E. The effect of vaccination and vaccine component upon short-term growth and feed conversion efficiency and body composition of rainbow trout. Aquaculture 1999; 174: 213-221.

[39] Sørum U, Damsgård B. Effects of anaesthetisation and vaccination on feed intake and growth in Atlantic salmon (Salmo salar L). Aquaculture 2004; 232: 333-341.

[40] Lund RA, Mydtlyng PJ, Hansen LP. Post-vaccination intraabdominal adhesions as marker to identify Atlantic salmon, Salmo salar L. escaped from a commercial fish farms. Aquaculture 1997; 154: 27-37.

[41] McLean E, Devlin RH. Application of biotechnology to enhance growth of salmonids and other fish. In: Fingerman M, Nagabhushnam R, Thompson MF, Eds. Recent Advances in marine biotechnology. Science Publishers Incorporated 1999, Enfield, New Hampshire, USA.
[42] Robertson L, Thomas P, Arnold CR, Trant JM. Plasma cortisol and secondary stress responses of red drum to handling, transport, rearing density, and a disease outbreak. Prog Fish-Cult 1987; 49: 1-12.

[43] Reddy PK, Leatherland JF. Stress Physiology. In: Leatherland JF, Woo PTK, Ed. Fish Disease, Volume III: Non-infectiosus disorders, CAB International 1988; 279-302.

[44] Barton BA, Iwama GK. Physiological changes in fish from stress in aquaculture with emphasis on the response and effects of corticosteroids. Annu Rev Fish Dis 1991; 1: 3-26.

[45] Tort L, Landri P, Altimiras J. Physiological and metabolic changes of sea bream Sparus aurata to short-term acclimation at low salinity. Comp Biochem Physiol 1994; 1: 75-80.

[46] Altimiras J, Champion SR, Puigcerver M, Tort L. Physiological responses of the gilthead sea bream Sparus aurata to hypoosmotic shock. Comp Biochem Physiol 1994; 108: 81-85.

[47] Benfey TJ, Biron M. Acute stress response in triploid rainbow trout (Onchorhynchus mykiss) and brook trout (Salvelinus fontinalis). Aquaculture 2000; 184: 167-176.

[48] Mazur CF, Iwama CK. Handling and crowding stress reduces number of plaque-forming cells in Atlantic salmon. J Aquat Anim Health 1993; 5: 98-101.

[49] Bourne PK. Changes in haematological parameters associated with capture and captivity of the marine teleosts, Pleuronectes platessa L. Comp Biochem Physiol 1986; 85A: 435-443.

[50] Waring CP, Stagg RM, Poxton MG. Physiological responses to handling in the turbot. J Fish Biol 1996; 48: 161-173.

[51] Montero D, Tort L, Izquierdo MS, Socorro J, Robaina L, Vergara JM, Fernández-Palacios H. Hematological recovery in Sparus aurata after bleeding. A time course study. Rev Esp Fis 1995; 51: 219-226.

[52] Montero D, Tort L, Izquierdo MS, Tort L, Robaina L, Vergara JM. Effect of $\alpha$-tocopherol and n-3 HUFA deficient diets on blood cells, selected immune parameters and proximate body composition of gilthead seabream (Sparus aurata). In: Stolen JS, Fletcher TC, Bayne CJ, et al. Eds. Modulators of Immune Response. The Evolutionary Trail. SOS publications, Fair Haven 1996; 251-266.

[53] Montero D, Izquierdo MS, Tort L, Robaina L, Vergara JM. High stocking density produces crowding stress altering some physiological and biochemical parameters in gilthead seabream, Sparus aurata, juveniles. Fish Physiol Biochem 1999; 20: 53-60.

[54] Thomas P, Woodin B, Neff JM. Biochemical responses of striped mullet Mugil cephalus to oil exposure. 1. Acute responsesinterrenal activation and secondary stress responses. Mar Biol 1980; 59: 141-149.

[55] Donaldson EM. The pituitary-interrenal axis as an indicators of stress in fish. In: Pickering AD, Ed. Stress in fish. London. Academic Press 1981; 247-275.

[56] Molinero A, Gòmez E, Balasch J, Tort L. Stress by fish removal in the gilthead sea bream, Sparus aurata. A time course study on the remaining fish in the same tank. J Appl Aquaculture 1997; 7: 1-12.

[57] Barcellos LJG, Nicolaiewsky S, de Souza SMG, Lulhier F. Plasmatic levels of cortisol in the response to acute in Nile tilapia, Oreochromis niloticus (L.) previously exposed to chronic stress. Aquaculture Res 1999; 30: 437-444.

[58] Cerdá-Reverter LM, Zanuy S, Carrillo M, Madrid JA. Time course studies of plasma glucose, insulin and cortisol in sea bass (Dicentrarchus labrax) held under different photoperiodic regimes. Physiol Behav 1998; 64(3): 245-250.

[59] Planas J, Gutierrez J, Fernandez J, Carrillo M, Canals P. Annual and daily variations of plasma cortisol in sea bass, Dicentrarchus labrax L. Aquaculture 1991; 91: 171-178.

[60] Ellis T, North B, Scott AP, Bromage NR, Porter M, Gadd D. The relationship between stocking density and welfare in farmed rainbow trout. J Fish Biol 2002; 61: 493-591.

[61] Morales AE, García-Rejón L, de la Higuera M. Influence of handling and /or anaesthesia on stress response in rainbow trout. Effects on liver primary metabolism. Comp Biochem Physiol 1990; 95A: 97-93.

[62] Nakano T, Tomlison N. Catecholamine and carbohydrate concentrations in rainbow trout (Salmo gairdneri) in relation to physical disturbance. J Fish Res Bd Can 1967; 24: 1701-1715.

[63] Wardle CS. The changes in blood glucose in Pleuronectes platessa following capture from the wild: a stress reaction. J Mar Biol Ass UK 1972; 52: 635-651. 
[64] Wendt CAG, Saunders RL. Changes in carbohydrate metabolism in young Atlantic salmon in response to various forms of stress. Spec Publs Int Atlant Salm Found 1973; 4(1): 55-82.

[65] Vijyan MM, Moon TW. Acute handling stress alters hepatic glycogen metabolism in food-deprived rainbow trout (Oncorhyncus mykiss). Can J Fish Aquat Sci 1992; 49: 2260-2266.

[66] Mock A, Peters G. Lysozyme activity in rainbow trout, Oncorhynchus mykiss (Walbaum), stressed by handling, transport and water pollution. J Fish Biol 1990; 37: 873-885.

[67] Kubilay A, Ulukov G. The effects of acute stress on rainbow trout (Oncorhynchus mykiss). Turk J Zool 2002; 26: 249-254.

[68] Maule AG, Shreck CB. Changes in numbers of leukocytes in immune organs of juvenile coho salmon after acute stress or cortisol treatment. J Aquat Anim Health 1990; 2: 298-304.

[69] Funk VA, Jones SRM, Kim E, et al. The effect of vaccination and sea water entry on immunocompetence and susceptibility to Kudoa thyrsites in Atlantic salmon (Salmo salar L.) Fish Shellfish Immunol 2004; 17: 375-387.

[70] Maule AG, Tripp RA, Kaattari SL, Schreck CB. Stress alters immune function and disease resistance in chinook salmon ( $\mathrm{On}$ corhynchus tshawytscha). J Endocrinol 1989; 120: 135-142.

[71] Montero D, Tort L, Robaina L, Vergara JM, Izquierdo MS. Low vitamin $\mathrm{E}$ in diet reduces stress resistance of gilthead seabream (Sparus aurata) juveniles. Fish Shellfish Immunol 2001; 11: 473490.

[72] Tort L, Sunyer JO, Gómez E, Molinero A. Crowding stress induces changes in serum haemolytic and agglutinating activity in the gilthead sea bream Sparus aurata. Vet Immunol Immunopathol 1995; 45: 333-345

(C) Maricchiolo et al.; Licensee Bentham Open.

This is an open access article licensed under the terms of the Creative Commons Attribution Non-Commercial License (http://creativecommons.org/licenses/by-nc/3.0/) which permits unrestricted, non-commercial use, distribution and reproduction in any medium, provided the work is properly cited. 